\title{
La Parroquia, punto neurálgico de la Pastoral Urbana ¿Cuál identidad y misión en la ciudad?
}

\author{
ANDREA PUENTES-RODRÍGUEZ* \\ Universitaria Uniagustiniana (Colombia) \\ andrea.puentes@uniagustiniana.edu.co
}

\begin{abstract}
Resumen
Este artículo busca analizar y hacer una lectura de la identidad, misión, ubicación y aporte que la parroquia ha venido realizando y tejiendo en relación con el contexto urbano. Al mismo tiempo desea comprender cómo ha incidido dicho fenómeno en el modo en el que la parroquia se ve y se lee, como también la manera en que se evidencian sus exigencias y los retos en tal contexto. Es de gran relevancia la pregunta sobre la identidad y la misión de la parroquia en la ciudad, ya que parecería muchas veces diluirse entre tantas propuestas y dinámicas que ofrece la ciudad y los desafíos que le ofrece el ser humano-urbano y el nuevo estilo de congregante. Por ello urge redescubrir su sentido más profundo, ya que, si la parroquia no tiene una clara identidad en medio de la ciudad, corre el riesgo de permanecer en su autorreferencialidad, perdiendo su dinamismo misionero.
\end{abstract}

Palabras clave: ciudad, parroquia, misión, identidad, teología, pastoral urbana.

\section{The Parish, neuralgic point of the Urban Pastoral What identity and mission in the city?}

\begin{abstract}
This article seeks to analyze and read the identity, mission, location and contribution that the parish has been making and weaving in relation to the urban context, at the same time understanding how this phenomenon has affected the way in which it is seen and it is read, as well, to show what their demands and challenges are in this context. The question about the identity and mission of the parish in the city is of great relevance, since it would seem many times to be diluted between so many proposals and dynamics that the city offers and the challenges that the human-urban being offers and the new style of congregant. For this reason, it is urgent to rediscover its deepest meaning, since if the parish does not have a clear identity in the middle of the city, it runs the risk of remaining in its self-referentiality, losing its missionary dynamism.
\end{abstract}

Key words: city, mission, parish, identity, theology, urban pastoral.

\footnotetext{
* Doctora en Misionología con especialización en Catequesis y Pastoral de la Pontificia Universidad Urbaniana de Roma - Italia. Actualmente se desempeña como docente en La Universitaria Uniagustiniana en Bogotá, sede Tagaste. Entre sus publicaciones recientes destaca "Jóvenes y Ministerios para la ciudad. Una vía pastoral” (2011), "El libro de Tobías. Rituales de sanación. Entre vida-muerte, ángeles-demonios” (con Maricel Mena López, 2019), "La misión y las Culturas” (2019).
} 
Mucho se dice de la parroquia sea para alabarla sea para recriminarla, poniendo en cuestión su presencia y pertinencia, su valor y su eficacia, más aún en el contexto urbano de la ciudad en el cual la parroquia se confronta con las dinámicas propias que la ciudad posee.

Esta relación entre parroquia y ciudad debe tener en cuenta el proceso de urbanización vivido en los dos últimos siglos y la nueva cultura que se constituye, que va haciendo que lo urbano se torne un desafío pastoral y multiplique los retos que se plantean a la misión de la Iglesia, exigiéndole responder con audacia evangélica.

La movilidad urbana ha puesto en crisis la parroquia de la ciudad, basada predominantemente en la comunidad territorial. Antes que la ciudad sea un lugar de residencia fija, comienza como un lugar de reunión al que la gente vuelve periódicamente. La capacidad para atraer a los no residentes, para el intercambio y el estímulo espiritual, subsiste, al igual que el comercio, destino esencial de la ciudad. (Zambrano, 2004: 15-16)

La parroquia se confronta con una gran realidad propia de su entorno de la cual debe concientizarse, y es que ella ya no sólo puede hablar de comunidades sino también de colectividades humanas que habitan el territorio, diversificándolo en múltiples grupos que se eligen cuando y como quieren. En la parroquia deberá producirse un giro paradigmático, reflexionando sobre su presencia en la ciudad y las exigencias que se le hacen de determinar cada vez más cuál es su identidad y su misión evangelizadora en este nuevo contexto, en el que parecería muchas veces diluirse ante las distintas propuestas y dinámicas que ofrece la ciudad y los retos que le ofrece el ser humano-urbano (Niño Sua, 1991: 180) en general y del discípulo misionero en particular para la ciudad.

Por ello urge redescubrir su sentido más profundo, ya que si la parroquia no reconoce quién es en medio de la ciudad, podría permanecer en su autorreferencialidad y encerrarse en sí misma, perdiendo su dinamismo misionero.

La Iglesia está llamada a encarnar el Evangelio también en la cultura urbana, ella se hace servidora de la ciudad y de los hombres que allí habitan, para asumir la tarea común de hacer cada día más visible el Reino instaurado por Cristo.

Este desafío es el que permite reflexionar sobre la parroquia como Iglesia local urbana, a quien se le pide reconocer que parte de su responsabilidad es redescubrir su vocación para hacer que el Evangelio descien- 
da a la realidad y provoque buenas noticias en la ciudad (Díaz, 1996: 207).

Es el tiempo de redescubrir la fisionomía de la parroquia, no tanto en razón de sus problemáticas sino de sus potencialidades en la urbe, para realizar plenamente su vocación y misión evangelizadora que, por un lado, propicie en los cristianos el deseo permanente de encuentro con Jesús y la alegría de vivir el Evangelio en la ciudad y, por otro, suscite el diálogo y la fe en aquellos que también habitan el territorio a través del testimonio evangelizador.

Si se asume este contexto urbano, se requiere asumir la cultura urbana como un desafio para la conciencia religiosa y para la vida cristiana, que exige renovar la evangelización y crear estructuras y estrategias eclesiales nuevas. Las exigencias y necesidades que se acrecientan plantean a la Iglesia el imperativo de rehacer allí, desde una dimensión trascendente, las relaciones consigo mismo, con los otros, con la naturaleza y con Dios (Rincón, 1989: 140).

Por tanto, este estudio ubica la relación parroquia-ciudad dentro del gran marco general Iglesia-ciudad. Solo en la medida en que se responda a la exigencia de identidad, la parroquia no aparecerá diluida en la ciudad, sino que ella tendrá un lugar significativo en la vida de los ciudadanos.

Discernir la pregunta planteada en el subtítulo de este estudio con respecto a la parroquia ¿Cuál identidad y cuál misión en la ciudad? será un imperativo que permitirá reflexionar sobre su actuar como fermento de Cristo en la sociedad citadina, renovándola y transformándola desde Él.

1. Parroquia: ¿QUiÉN ERES TÚ EN LA CIUDAD? ALGUNAS COMPRENSIONES DE LA PRESENCIA DE LA PARROQUIA EN LA CIUDAD

Esta mirada de análisis contemplativo sobre la parroquia en el contexto urbano que conlleva a una primera reflexión tiene como finalidad tomar conciencia de lo que la parroquia está siendo hoy en y para la ciudad.

La parroquia urbana se encuentra retada evangélicamente por los nuevos fenómenos civiles de movilidad, del urbanismo industrial, de la débil pertenencia, entre otros; lo que ha generado relaciones funcionales, formas de agregación flexible, elástica o a distancia.

La globalización como uno de los fenómenos más impactantes, ha estado reconfigurando el mundo, y sigue y seguirá haciéndolo, a una velocidad sin precedentes. Este proceso se manifiesta en un mundo hiperactivo y conectado las 24 horas a las redes telemáticas, fenómeno tan característico y a la orden de nuestro tiempo. La misión no puede ser hoy 
pensada, vivida o actuada si no teniendo presente un mundo globalizado y actuándose de modo global.

La pluralidad, es otro de los fenómenos que viven también las ciudades y en el cual la convivencia se construye día a día a partir de la persona y de sus opciones, a veces, sin embargo, fuertemente condicionadas por una cultura global que tiende a imponer la "dictadura del relativismo, proponiendo modelos antropológicos incompatibles con la naturaleza y dignidad del hombre", sembrando incertidumbres, desarraigos y confusiones. Ante la gran acumulación de informaciones, con inmensos cambios promovidos por la ciencia y la tecnología y por una nueva concepción de libertad religiosa, se desvanece una única imagen del mundo, del ser humano y de Dios, que ofrecía orientación para la vida cotidiana (Consejo Episcopal Latinoamericano, 2007: n.57). Esta pluralidad debemos aprender a leerla no como un obstáculo que hay que vencer, sino como un elemento de plenitud de la encarnación. Esto supone un testimonio siempre abierto, acogedor; un testimonio que tiene la capacidad de crear comunión en la pluralidad (Barreda, 2003: 341).

Junto al pluralismo se encuentra también una emergencia de subjetividad en la que cada uno puede escoger, de la plural oferta de sentidos y prácticas sociales, lo que le parece mejor. La emergencia de la subjetividad ha significado una importante conquista de la humanidad. La dignidad y la libertad de la persona humana son reconocidas y respetadas. Las raíces de ello están ciertamente en la novedad del cristianismo, aunque hayan pasado por vicisitudes históricas y culturales. Actualmente ésta subjetividad se reduce a un mero subjetivismo, hostil a cualquier vínculo, sin referencia a la verdad, sin unidad interior, y dañino para la convivencia social (Consejo Episcopal Latinoamericano, 2007: n.58).

Estos tres grandes fenómenos que viven intensamente y en modo particular las ciudades, sirven de telón de fondo de muchas de las dinámicas que ellas viven y que impactan en todo sentido a sus habitantes, repercutiendo sin duda también en la vida de fe.

Este tiempo particularmente en el cual el mundo ha vivido tan de cerca la fragilidad de nuestra existencia frente a la pandemia provocada por el Covid 19, también la parroquia ha tenido que hacer frente a la debilidad de su organización, su acción, su presencia, su incidencia, su construcción de tejido relacional, espiritual, pastoral y social en medio de la ciudad.

Ahora más que nunca preguntar a la Parroquia ¿Quién eres tú en la ciudad? es de capital importancia porque hace referencia a su identidad.

Así como las ciudades no son la suma de sus edificios, sus autopistas, sus zonas industriales, etc., más son en cuanto tales por las personas que la conforman, de igual manera la parroquia no es la suma de los templos, ni las extensiones geográficas de sus territorios, entre otras; sino 
que son las personas, los ciudadanos, las comunidades humanas, los cristianos, en este sentido y por ello la pregunta va dirigida a personas concretas que de una u otra manera buscan la renovación parroquial y de sus agentes para que ésta responda cada vez mejor al desafío evangelizador en la ciudad.

Algunos aportes de agentes evangelizadores ${ }^{1}$ serán apoyo en esta disertación, como lo reflexionado en la CV Asamblea Plenaria del Episcopado Colombiano (Conferencia Episcopal de Colombia, 2018) sobre la parroquia, permitiendo dirigir una mirada no solo creyente sobre ella sino también una mirada profética en su relación con la ciudad.

La Instrucción de la Congregación para el Clero sobre la conversión pastoral de la comunidad parroquial al servicio de la misión evangelizadora de la Iglesia, recuerda que los notables cambios sociales y culturales de los últimos decenios han inducido, a diversas iglesias particulares, a reorganizar la forma de encomendar la cura pastoral de las comunidades parroquiales (Congregación para el Clero, 2020).

Con respecto a la relación que se gesta entre parroquia y ciudad, parecería que cada vez más la imagen de parroquia con sus pros y sus contras se está entendiendo como una realidad que va más allá del templo, de su estructura física y de su geografía. El criterio de lo urbano exige a los evangelizadores actuar como tal. La parroquia en la ciudad está buscando de un modo u otro, aunque a veces a tientas, un acercamiento y una mejor relación con la ciudad.

Para buscar comprender y tener mayor claridad de cuál es la identidad y misión de la parroquia en la ciudad, propongo hacerlo a través de los siguientes marcos de lectura: Marco Antropológico-sociológico, Marco Pastoral, Marco teológico.

\subsection{Marco Antropológico-sociológico}

La parroquia se define por su eclesialidad y su presencia y su vinculación a un territorio (Francisco, 2013: n.28) y por ende a las personas y a la comunidad que allí habitan.

Esta realidad eclesial de la parroquia, puede decirse que nace del deseo de proximidad con las personas, quienes desde los primeros siglos del cristianismo ya comenzaban a movilizarse hacia las ciudades. Si bien este deseo haya sido "contaminado" por diversos factores, el impulso de fondo ha sido siempre el de acompañar a la comunidad y a las personas

Se aplicó un cuestionario Parroquia ¿Quién eres tú en la ciudad? Al cual accedieron a responder algunos agentes evangelizadores en el primer semestre del año 2020 , respuestas y testimonios que se han tomado en cuenta en el presente artículo. 
en la fe y consecuentemente permanecer cercanos a los espacios en los cuales desarrolla su vida.

En la actualidad no pocas parroquias atraviesan momentos de dificultad a causa de las transformaciones demográficas, los continuos cambios en el territorio o porque algunos desafíos pastorales superan su capacidad organizativa, lo que hace que se evidencie una necesidad de apoyo y acompañamiento (Salamanca Mantilla, 2019).

Es necesario pensar o definir la parroquia, más que como una comunidad de fieles, como comunidad humana, integrada por personas concretas, con una carga de valores y contravalores que conlleva todo grupo social. Ciertamente la parroquia, es comunidad integrada por personas que se agrupan y se cohesionan por lazos de fe, pero que al igual se caracteriza por rasgos propios de un grupo humano. Cabe destacar que en la mayoría de los casos entre los feligreses están casi ausentes las relaciones interpersonales, lo que no ayuda en la construcción de una identidad como comunidad. Estos factores son condicionantes y habrá que tenerlos en cuenta en la actividad pastoral y en la revitalización de esta, reconociéndola como comunidad de talla humana, lo que resalta y valora su perfil antropológico y social (Rodríguez Carrasco, 2014: 184-185).

Si bien se reconoce que la parroquia es una comunidad de fieles, también debe reconocerse que es una comunidad humana compuesta por otros que se acercan y buscan ser escuchados, ser recibidos, que piden que no se les excluya, sino más bien, que se acojan a ejemplo de Jesús.

Un acercamiento fenomenológico a la realidad concreta del hombre urbano, hace evidente los múltiples retos que la cultura urbana ofrece a la evangelización y la necesidad de un profundo discernimiento por parte de la Iglesia, que le permita anunciar el Evangelio a un tipo de persona que tiene un modo característico de ser, de vivir y de convivir, de sentir y de pensar, de trabajar, que confía en la ciencia y en la tecnología; está influido por los grandes medios de comunicación social; es dinámico, abierto, extrovertido y proyectado hacia lo nuevo; consumista, audiovisual, anónimo en la masa y desarraigado. Este nuevo estilo de hombre y de mujer, hace de la urbe lugar y ocasión de comunicación, que urge y exige "comunicadores que tengan los mensajes adecuados para el hombre de hoy, y a la vez, comunicadores que conozcan cómo habla la ciudad de hoy, qué dice, qué necesita" (Méndez, 1990: 58).

La parroquia en la ciudad está haciendo el intento por no permanecer al margen de la realidad que vive la persona urbana. No obstante, Se advierte que se deben hacer mayores esfuerzos por conocer las realidades para poder alcanzarla con la fuerza del Evangelio, construyendo una comunidad viva y en salida misionera. Hay una valoración de los esfuer- 
zos que desde la parroquia y desde sus mismos agentes se van tejiendo a nivel social, cultural y espiritual, pero se reconoce que frente a la ciudad las acciones no son eficaces, las mismas parroquias se reconocen insuficientes y no es fácil la misión. Frente a situaciones como la pobreza, el desempleo, el consumo de drogas y la violencia se trata de intervenir a través de la educación de la fe y los valores evangélicos, para evitar o corregir dichas problemáticas.

Con el crecimiento de las propiedades habitacionales horizontales en las ciudades, que son casi el reflejo de un oasis en medio del desierto o en medio del caos, ha sido una constante preocupación por cómo acceder en la ciudad a dichas zonas que parecen estar amuralladas por sus administraciones y vigilantes. Sin embargo, este tiempo de pandemia que afrontamos, ha hecho que la relación pase por el uso de canales digitales que trasciende toda frontera, permitiendo la entrada en los hogares y superando los inconvenientes mencionados, entre otros muchos posibles. A través de estos canales se han ofrecido espacios de formación, de oración, de encuentro fraterno, de diálogo sobre temáticas actuales, formación sacramental, etc.

Dentro de esta territorialidad cada vez más fluida, muchas personas ya no se identifican con un único lugar de residencia o pertenencia. Asistimos así a otra compleja dinámica: la de la población flotante como en sectores o zonas empresariales e industriales, comerciales, turísticas o recreativas, etc., donde aparentemente no se puede hacer mucho o mejor aún no se tiene una pastoral atípica como hablará Francisco Merlos, para ofrecer a dicha población en estos territorios.

Se considera también como reto para algunas parroquias el incremento de la tasa de viviendas en arriendo lo cual no permite hablar de una comunidad de referencia fija y el envejecimiento de la población de algunas zonas. Contrariamente a esta realidad, algunos sectores cuentan con una alta población de jóvenes y niños y el reto radica en conocer la manera más efectiva y el modo de proponer el Evangelio a cada uno de estos grupos humanos.

Hoy las parroquias en la ciudad pueden tipificarse según el contexto donde hacen presencia, es decir, parroquias que asumen características particulares según sean los integrantes de su comunidad, como una forma de hacer presente el Evangelio en un contexto específico. Por ello encontramos parroquias en zonas empresariales, en barrios, en zonas de tolerancia, parroquias en medio de conjuntos residenciales, etc.

Haciendo referencia a zonas de tolerancia, entendidas así por contar con presencia de personas como (los más pobres, migrantes, comunidades LGBTI, trabajadoras sexuales, vendedores ambulantes, artistas callejeros, consumidores) que podrían ser los "descartados" o los "sobrantes" 
de la sociedad como lo ha dicho el Papa Francisco (2013, n.53), ésta es una situación que atañe a todas las ciudades por lo general. El arzobispo de Bogotá Monseñor, José Luis Rueda Aparicio reconoce que los habitantes de estas zonas no sólo son excluidos socialmente, sino que ellos se autoexcluyen también en el campo religioso.

Se piensa que la creación de parroquias para esta ciudadanía sería un gran acto de parresia, pues "Muchos de ellos no van a las iglesias, por su propia condición se autoexcluyen".

La parroquia es una realidad en la que confluyen de una manera explícita o implícita, todos los problemas históricos de la pastoral eclesial actual. (“La eclesiología de la comunión y su aporte a la pastoral ...”). Es, pues, un espacio que plantea muchas dificultades y desafíos, pero al mismo tiempo es un espacio privilegiado para plantearse la búsqueda de caminos de futuro para la renovación de la pastoral.

La institución parroquial es una realidad antropológica y social a la que van a parar todas las problemáticas de las personas y de los colectivos humanos. Esto hace que no solo sea un espacio privilegiado para la búsqueda pastoral, sino también un lugar privilegiado para la observación de la situación contemporánea de la humanidad (Prat i Pons, 2005: 303).

La parroquia debe saber cada vez más integrar la propia propuesta con los múltiples territorios "antropológicos" con los cuales entra en contacto, ayudando a interpretar, a interactuar y a producir testimonios creíbles según los contextos.

\subsection{Marco Pastoral}

Como primer paso al abordar este marco de lectura pastoral de la parroquia en la ciudad, considero necesario reconectarnos con la tarea que como Iglesia estamos llamados a realizar, y que mejor que recordarlo desde la Novo Millennio Ineunte:

El programa ya existe ... Se centra, en definitiva, en Cristo mismo, al que hay que conocer, amar y seguir, para vivir en Él la vida trinitaria y transformar con Él la historia hasta su perfeccionamiento en la Jerusalén celeste. Es un programa que no cambia al variar los tiempos y las culturas, aunque tiene cuenta del tiempo y de la cultura para un verdadero diálogo y una comunicación eficaz. (Juan Pablo II, 2001: n.29)

De aquí en adelante se da inicio al desafío pastoral de la Iglesia en cada contexto, pero particularmente desafiada por el contexto urbano de la ciudad y sus dinámicas propias. 
En la CV Asamblea Plenaria del Episcopado Colombiano, tomando enserio la reflexión sobre la parroquia como en muchas otras Conferencias Episcopales propias de cada país y sus respectivas diócesis, la Iglesia se interpela también por la identidad y misión de la Iglesia.

En la Asamblea los obispos tuvieron ocasión de acercarse a la realidad de las parroquias: sus características, su entorno y los desafíos que enfrentan, sus fortalezas y debilidades.

La Asamblea partiendo de la Christifideles laici, de San Juan Pablo II, hace conciencia de que es necesario que todo volvamos a descubrir, por la fe, el verdadero rostro de la parroquia; o sea, el misterio mismo presente y operante en ella. De antemano la exhortación nos aclara lo que no es la parroquia; no es una estructura si bien ella deba contar con una organización para operar, no es un edificio si bien sus templos son reflejo de la presencia eclesial, no es un territorio si bien ella deba hacer parte de una ubicación en el mismo (Juan Pablo II, 1988: n.26).

Se valora la presencia de grupos parroquiales y pequeñas comunidades, creación de espacios formativos que se procuran para los agentes de pastoral, presencia de acciones misioneras, trabajo conjunto entre parroquias y la presencia de comunidades de vida consagrada, se siguen planes pastorales, y se mantiene activa la iniciación cristiana y la vida sacramental, se valora positivamente la presencia y participación de los laicos en la pastoral y la inserción social dentro del territorio.

Sin embargo, frente a los cambios que se deben hacer en relación con la visión de la parroquia, son los sacerdotes quienes en su discernimiento evidencian que se debe trabajar por mejorar el sentido misionero y el sentido de pertenencia de los fieles, mejorar los procesos de evangelización, mejorar los tiempos que el sacerdote dedica para atender a los fieles y su servicio. La parroquia deberá hacer un mayor esfuerzo por impulsar la pastoral familiar, fortalecer la fraternidad interna de la comunidad y en su relación con otras comunidades eclesiales, descentralizar ciertas acciones de la parroquia o templo principal, renovar el corazón de los fieles, incrementar la formación presacramental.

Los laicos por su parte observan que debe favorecerse e incrementarse la formación de los agentes de pastoral, formando en la participación de ellos a las distintas tareas de la Iglesia y potenciando su liderazgo. Esta petición no es nada nueva y es siempre una imperante exigencia, ya que los laicos quieren estar mejor preparados para ofrecer un mejor servicio evangelizador, más aún frente a los retos y desafíos de la ciudad.

También se observa una exigencia de inclusión en la vida de la parroquia, comprendiendo que la misión evangelizadora es tarea de todos y no sólo de los sacerdotes. Favorecer la construcción de una autentica comunidad fraterna, donde se acreciente el sentido de pertenencia de los 
fieles con su parroquia. Ella debe incidir más en el ámbito social y fortalecer la caridad, se debe trabajar por mejorar la presencia espiritual del sacerdote en los distintos lugares de la comunidad parroquial siendo cada vez más pastor que administrador, pasar de una pastoral sacramental a una pastoral misionera. La vida litúrgica, expresan los laicos, deberá también ser mejorada en su lenguaje, en su significación y expresión simbólica. La parroquia debe trabajar por pasar de una religiosidad popular a una espiritualidad más Cristocéntrica, suscitar pequeñas comunidades radicadas en el estudio y en la centralidad de la Palabra de Dios.

Por parte de las mismas parroquias urbanas, se reconoce el esfuerzo pastoral que los grupos parroquiales están haciendo por mantener una activa comunicación con el entorno de su territorio urbano parroquial y que en muchos casos son creadores de propuestas que permiten visibilizar la acción pastoral en medio de diversos territorios que la componen, se destaca la inserción que la parroquia ha tenido en lo social, en medio de las realidades más alejadas y vulnerables propendiendo por la creación de espacios que generen mejor calidad de vida y construcción de comunidad humana y cristiana (Conferencia Episcopal de Colombia, 2018: 913).

Las ciudades y las parroquias encuentran en la persona su sujeto común, a la cual desean acoger, promover, integrar, dentro de su misión y sus propuestas a través de distintos espacios, tiempos y lugares "El objeto de esta premura es el hombre en su única e irrepetible realidad humana, en la que permanece intacta la imagen y semejanza con Dios mismo" (Juan Pablo II, 1979: n.13).

Con respecto al compromiso de los laicos y su participación en las distintas acciones en la ciudad, se logra llamar y cautivar la atención de algunos residentes que se involucran en las propuestas y programas que se imparten y comparten, pero es también una realidad, que hay una crisis de compromiso cristiano en las distintas propuestas de la parroquia por ocupaciones diversas, pero fundamentalmente ligadas a lo laboral. Sin embargo, se sabe también que se puede hacer algo más y llevar a la comunidad a ser algo más, que sólo una comunidad de misa, a construirse como comunidad de la misericordia y misericordiosa, buscando nuevas formas de suscitar en los ciudadanos el compromiso y atraerlos hacia el camino del Evangelio.

En la ciudad se hace un discernimiento sobre un aspecto que en lugar de enriquecer debilita la pastoral y la participación en los grupos pastorales, en los cuales se evidencia que en algunas ocasiones hay servidores que participan en dos o tres grupos a la vez, lo cual implica un desgaste y efecto de no alcanzar a cumplir todos los compromisos. 
Al inicio se proponía la pregunta ¿cómo definir la parroquia en la ciudad? Algunos encuentran en la categoría de familia el mejor modo para definirla, lo cual implica la comprensión de un territorio y de unos sujetos urbanos. Una gran familia comunidad, que acoge a cada ser humano creyente y no creyente. Este sentido de familia que se tiene de la parroquia en la ciudad conlleva a sentirse llamado a hacer parte de esa familia, sentirse querido, pero también responsable por mostrar el amor del cual se nutre, ser Evangelio vivo en medio de la realidad clara y oscura en la que se mueve la sociedad actual, transmitiendo la certeza de Cristo por medio de la alegría que produce el reconocerse hijo de Dios. Es comunidad de bautizados que bajo el cuidado del párroco viven la ley de Cristo y buscan ser discípulos misioneros en una ciudad necesitada de acciones concretas de la misericordia de Dios para experimentar su acción liberadora. Es ser testimonio fiel del amor de Dios, en diálogo con las demás creencias, oración, vida y misión. Es una comunidad de innovación y de retos urbanos y finalmente es ser lugar de encuentro y vivencia de los sacramentos.

La CV Asamblea Plenaria también vislumbró posibles caminos para la renovación de la parroquia. En este sentido se retomó la V Conferencia General del Episcopado Latinoamericano y del Caribe de Aparecida que insiste en la renovación de las parroquias, y definió su deber ser como red de comunidades y grupos, capaces de articularse logrando que sus miembros se sientan y sean realmente discípulos misioneros de Jesucristo en comunión.

Toda parroquia esta llamada a ser el espacio donde se recibe y acoge la Palabra, se celebra y se expresa en la adoración del Cuerpo de Cristo, y así es la fuente dinámica del discipulado misionero (Consejo Episcopal Latinoamericano, 2007: n.172).

Otro elemento, al parecer que viven las parroquias constantemente y que merece ser tenido en cuenta, es la vivencia del criterio del "siempre se ha hecho a sí y vamos bien" lo que se opone a nuevas propuestas y a la adecuación y ejecución de planes pastorales con sello propio.

No obstante, los desafíos y los intentos por ser mejor presencia de Iglesia en la ciudad, considero que aun hoy podemos afirmar con Ecclesia in Europa, que a pesar de las complejas transformaciones la parroquia conserva y ejercita una misión indispensable y de gran actualidad, en el ámbito pastoral y eclesial. Sin duda, la parroquia ha sabido aportar elementos que deberán ser destacados (un espacio para el ejercicio efectivo de la vida cristiana, lugar de auténtica humanización y socialización) y en ningún caso perdidos, cualquiera que sea el modo de su reformulación (Juan Pablo II, 2003a: n.15). (Domingo \& Segovia Bernabé, 2013). 
Ahora bien, la parroquia constituye el rostro más visible de la Iglesia, por ello es comprensible que sobre ella hayan caído todas las presiones y exigencias.

Se ha llegado a pensar que la parroquia es una estructura caduca, pero en contraposición a esta teoría los documentos del magisterio pastoral de la Iglesia revocan tal afirmación, tal es que el Papa Francisco (2013: n.28) afirmará todo lo contrario, aludiendo que ella tiene una peculiar característica de plasticidad, que le permite tomar formas muy diversas, que requiere eso sí, de docilidad y creatividad, sea por parte del pastor sea por parte de la comunidad.

Pastoralmente la parroquia se confronta con distintos retos que la han puesto en crisis. Uno de ellos que en verdad la ha sacudido y la ha sacado de su acomodamiento es la movilidad urbana exigiéndole reflexionar sobre la configuración de su comunidad, el replanteamiento de los lazos que los une, las relaciones que se construyen con el entorno y los intereses del hombre urbano que trascienden la geografía (Bestard, 1984).

El Papa Francisco sostiene que la parroquia es presencia eclesial en el territorio (Francisco, 2013: n.28) y este término de la presencialidad hace referencia no sólo a encontrarse en un lugar determinado sino al hecho de estar posicionados hacia el otro y en favor del otro (Salamanca Mantilla, 2019). Esto hace que, por lo tanto, sea mucho más que una estrategia operativa de lo pastoral.

El hombre actual, a consecuencia de la moderna separación entre familia y mundo del trabajo, vive en diferentes ámbitos y contextos y tiene que ser abordado en modo adecuado y diferenciado. Una exigencia unilateral de la parroquia resulta obsoleta por la movilidad actual (Díaz, 1996: 42).

Es claro que en los contextos urbanos las parroquias no se componen solamente de fieles que tienen el lugar de residencia en aquel territorio, pero es también cierto que un nomadismo espiritual no es tampoco el ideal. Los católicos deben tener una comunidad parroquial que sea punto de referencia para su vida espiritual y de confrontación con la exigencia evangélica y de vida comunitaria. En este sentido sería más apropiado decir "soy parroquia" en lugar de decir "pertenezco a esta parroquia" en el sentido de simplemente estar domiciliado allí (Salamanca Mantilla, 2019).

Esta perspectiva de la movilidad hace que entren en juego las dinámicas del tiempo y del espacio en las ciudades. El tiempo es un factor que el hombre y la mujer urbanos creen nunca tener. El tiempo no les pertenece, al menos así lo sienten. No sólo es una carencia de tiempo real, consecuencia de la carga laboral y de la movilidad, sino además es una mentalidad que se contagia. El desempleado dirá lo mismo: "no ten- 
go tiempo". Si la gente no tiene tiempo, en vano multiplicar espacios de encuentro. El tiempo sufre grandes transformaciones en la vida urbana, la pluralidad de ofertas de pasatiempos de la ciudad y evolución tecnológica provocan modificaciones significativas. Este fenómeno reduce cada vez más los momentos para lo religioso y prolonga las horas ante los televisores, las computadoras y los Smartphone.

De otro lado se acentúa la relevancia del lugar/espacio, como lugar/interés, en la configuración de las relaciones humanas. Aquí este desplazamiento conceptual y existencial del lugar que se da en las experiencias humanas, tendrán que pasar por una resignificación de los espacios para que ellos se tornen vitales, y la parroquia cada vez más sea vista en su búsqueda de lugares y espacios de diálogo, de anuncio, que revitaliza los contextos eclesiales, haciéndolos lugares de testimonio creíble, capaces de acompañar los procesos de crecimiento de la fe.

La parroquia en su revitalización deberá atender pastoralmente lugares afectivos, relacionales, sociales, mentales.

En este debatirse entre el tiempo y el espacio, entre las múltiples funciones que la persona urbana y cristiana debe afrontar, sean ellos clérigos, agentes pastorales laicos, fieles y habitantes se enfrentan a algo que el psicólogo Milgram presenta como la teoría de la sobrecarga, la cual se justifica en que "la vida en la ciudad tal y como es experimentada, constituye una serie continua de interacciones" y, por otro lado "consiste en dar menos tiempo a cada persona o a cada encuentro". La sobrecarga característicamente deforma la vida cotidiana e incide en el desempeño de roles, afectando en esas mismas dinámicas las prácticas del impulso samaritano y garantizando el anonimato en este tipo de situaciones (Corraliza \& Aragones, 1993: 413). Las tareas aumentan dentro del sistema parroquial tradicional, sobrecargando a los párrocos y a sus equipos.

La mentalidad misma de la ciudad empuja a insertarse en ese movimiento planetario constituido por algunas dinámicas que les son propias como la velocidad, la utilidad, el anonimato, permeando no pocas veces la acción pastoral de la ciudad, debiendo responder con esas mismas dinámicas a los procesos formativos, evangelizadores, propuestas y programas, momentos celebrativos; convirtiendo a la parroquia y su acción en una respuesta de utilidad en algunos momentos de la vida. Esto afecta la presencia de la parroquia en la ciudad, haciéndola una presencia contradictoria. Porque a la vez que acompaña, muchas veces propicia por la misma velocidad y utilidad, una incorporación a la comunidad eclesial más sociológica que verdadera, y su praxis pastoral, se convierte más en un factor de conservación social que fuente inspiradora de transformación de la ciudad (Díaz, 1996: 208). 
La parroquia tiene una centralidad dentro de la Nueva Evangelización y la necesidad de una renovación interior de todos los miembros de las comunidades parroquiales para volver a descubrir su verdadero rostro (Maestro, 2012: 8).

No es que la parroquia sea caduca, pero si debe "abandonar estructuras caducas que ya no sirven para la transmisión de la fe" (Consejo Episcopal Latinoamericano, 2007: n. 365). Se trata de una renovación que exige actitudes nuevas en los párrocos, en los sacerdotes (2007, n. 201). Una parroquia renovada multiplica las personas que realizan servicios y aumenta los ministerios (2007: n. 202). Sólo "a través de la multiplicación de ellos" se puede responder a las exigencias de nuestro tiempo. Esto exige de parte de los pastores, mayor apertura de mentalidad (2007: n. 213). Los mejores esfuerzos de las parroquias (...) deben estar en la convocación y en la formación de los laicos, cuyo campo específico es "el mundo del trabajo, la cultura, las ciencias y las artes, la política, los medios de comunicación y la economía, así como de los ámbitos de la familia, de la educación, de la vida profesional" (2007: n. 174). (Suess, 2010: 103-104).

En este marco de realidad de la parroquia bien se puede decir que:

La renovación de la evangelización requiere nuevas tareas y propuestas pastorales diversificadas, para que la Palabra de Dios y la vida sacramental puedan alcanzar a todos, de manera coherente con el estado de vida de cada uno. De hecho, hoy la pertenencia eclesial prescinde cada vez más del lugar donde los fieles han nacido o se han criado, y se orienta más bien hacia una comunidad de adopción, donde estos hacen una experiencia más amplia del Pueblo de Dios. (Congregación para el Clero, 2020: n.18)

Una particular atención merece dársele al cultivo en el territorio de correctas relaciones, no hegemónicas ni subalternas, en relación con las instituciones públicas con las cuales la comunidad parroquial entra en contacto, también en el servicio a los pobres. Esto será posible a partir de las mismas razones de una identidad cristiana capaz de ponerse en modo vital con el espacio y el tiempo de lo social.

\subsection{Marco teológico}

Las comunidades parroquiales con sus sistemas arquitectónicos hacen visible la presencia de Dios en medio de nuestras ciudades; son un signo de la solicitud de Dios que quiere salir al encuentro de todos sus hijos. 
La misión que se le ha confiado es la de anunciar el Reino de Dios, proclamándolo con su vida y testimonio en corresponsabilidad con todo el pueblo de Dios. Ella también tiene que ser fiel a su misión espiritual sin renunciar a la solidaridad/fraternidad con toda la humanidad. el amor cristiano no se limita a la comunidad tienen que fraguarse en ella para salir de ella.

En los barrios de las actuales ciudades, las iglesias parroquiales son por definición iglesias abiertas a todos; cada persona que quisiera entrar debería poder hacerlo, sin necesidad de credenciales de pertenencia o de una invitación particular. Este signo no es banal, más bien es signo del deseo divino de acercarse a todos y de hacerse partícipe de todas nuestras vicisitudes (Salamanca Mantilla, 2019).

La legítima autonomía de las realidades terrenas nos conduce a reconocer el mundo, más que como un escenario, como un interlocutor del Reino y de la evangelización, de quien se aprende, a quien se está llamado a conocer y comprender cómo son sus leyes y dinámicas propias, para saber discernir los signos de la presencia de ese Reino de Dios, y para saber desarrollar la presencia y acción evangelizadora de la Iglesia (Mancera Casas, 2015: 46).

La parroquia, es una presencia pública que habla del carácter esencialmente público del mensaje cristiano y del interés que este tiene por hacer que la fe desarrolle estrategias para "promover la justicia social y global". La Iglesia no sólo no renuncia a estar presente en la ciudad, sino que una parte esencial de su misión consiste en ayudar a configurar un orden social más humano.

La XIII Asamblea General Ordinaria del Sínodo de los Obispos sobre el tema "La Nueva Evangelización para la transmisión de la fe cristiana", señala que la parroquia es la Iglesia, "que vive entre las casas de sus hijos y de sus hijas" (Sínodo de los Obispos, 2012: n.83). Al ser ella un espacio privilegiado para tener experiencias de comunión en la misión, le corresponde un particular rol en la transmisión de la fe (Sínodo de los Obispos, 2012: n. 167). Pero esto que señalan en el aula sinodal podría quedar en el papel si ella misma no acepta este desafío, posibilitando en su interior una renovada experiencia comunitaria de la fe.

La parroquia, en cuanto continuadora de la Pascua/Pentecostés, ha de situarse entre el cenáculo y el ágora. Su estar sin ser del mundo la configura para que se abra a una universalidad centrífuga, para ser una Iglesia que, en su multitud de rostros y nombres, ofrece en la comunión-misión múltiples caminos, procesos y ofertas: es una Iglesia de puertas abiertas (Calvo Pérez, 2016: 180).

Es necesario que todos volvamos a descubrir, por la fe, el verdadero rostro de la parroquia; o sea, el "misterio" mismo de la Iglesia presente y 
operante en ella. Ella es ante todo "la familia de Dios", como una fraternidad animada por el Espíritu de unidad, es una casa de familia, fraterna y acogedora (Juan Pablo II, 1988: n.26).

\section{OPCIONES OPERATIVAS DE LA PARROQUIA EN LA CIUDAD}

Teniendo en cuenta lo ya expresado, se plantearán algunas opciones operativas que expresen una transformación de la parroquia más consciente y consecuente con el contexto de la ciudad y la lleve a ser cada vez más parroquia evangelizadora y educadora de la fe de sus ciudadanos.

Se trata ahora más que nunca en pensar la parroquia de la ciudad, no con nuevas estructuras, si bien como se decía antes ella necesita una organización, sino más bien un cambio de paradigma de su presencia en el territorio, una verdadera conversión parroquial.

Debemos partir de la premisa que la parroquia no debe ser considerada como una "distribución funcional de la diócesis, sino, por un lado, "forma histórica privilegiada de la localización de la Iglesia particular" a través de la cual "la diócesis expresa la propia dimensión local", y por otro lado, debe ser considerada como el espacio donde se hace experiencia de ser Pueblo de Dios en cada ciudad, como se evidencia en cada una de las cartas de San Pablo (González Dorado, 1983: 92).

Partiendo de esta connotación, a continuación, se presentan algunas notas que pretenden diseñar o perfilar el rostro de la parroquia en la ciudad, para servir mejor al Reino de Dios en ella.

\subsection{Parroquia como casa de la comunidad}

Cada vez más debemos pasar del templo como "no lugar" entendido este como un espacio sin identidad, anónimo, impersonal, a la parroquia entendida como "una casa que vive entre las casas de sus hijos e hijas", "comunidad de comunidades" (Francisco, 2013: n.28).

La evangelización pasa por el lugar principal que son las relaciones humanas como base para el anuncio. Existe una emergencia de construir tejido humano relacional, capaz de interesarse por la persona, de acogerla, acompañarla en su propio caminar, teniendo en cuenta su historia y sus procesos personales. Hoy se comprueba ampliamente que el éxito y el fracaso de la vida y el trabajo depende en gran medida de la calidad o falta de calidad que haya en las relaciones con los demás (Merlos Arroyo, 2002: 93).

Se olvida que la relación puede abrir o cerrar las puertas en una acción pastoral. Pocos entienden que gran parte de los problemas pastorales son problemas de relaciones interpersonales. La calidad de las rela- 
ciones pastorales no es una cuestión secundaria. Se sostiene en la calidad de las relaciones humanas. Y muchas veces será el argumento más fuerte para mostrar que vale la pena dejarse seducir por el Evangelio. Los discursos no tendrán valor si no estamos en capacidad de ofrecer a las personas un trato digno, respetuoso y no excluyente (Merlos Arroyo, 2002: 94).

El buen trato, las buenas relaciones no miran sólo al externo, son tanto o igualmente importantes al interno de la Iglesia, entre los evangelizadores y pastores, muchos se van decepcionados y otros hasta abandonan la Iglesia por no encontrar en ella una elemental acogida fraterna. Los evangelios son prueba que las relaciones pastorales de Jesús son al mismo tiempo relaciones profundamente humanas. Relaciones que promueven y respetan a la gente, la animan y la reconfortan para la lucha diaria. Relaciones que dignifican a las personas. Las relaciones personales dentro de las parroquias más extensas son de gran importancia, deben tener en cuenta las particularidades antropológicas, culturales y sociales, permitiendo renovar y profundizar la vida de comunión (Merlos Arroyo, 2002: 95-96).

El hecho de que las parroquias se encuentren en medio de las calles, visibles a todos, es una oportunidad para mostrarles que Dios Padre, viene al encuentro de todos y acoge a todos. En una parroquia cada persona debería poder sentirse acogido a prescindir de las propias creencias, del nivel sociocultural o del tipo de relación con la Iglesia. La imagen de parroquia como casa, y casa de puertas abiertas adquiere actualidad en medio de los cambios positivos en tantas de las actuales ciudades, donde se supera la desconfianza enfermiza y se busca integrar a los diferentes, haciendo de dicha integración un nuevo factor de desarrollo (...) que favorece el reconocimiento del otro (Francisco, 2013: n.210). La presencia de la parroquia en la ciudad debería sugerir que ellas son espacios de encuentro con Dios y los creyentes, pero también de los creyentes con los todos los demás ciudadanos.

2.2. Parroquia como escuela de santidad, laboratorio de la fe y palestra de formación

Toda parroquia posee su papel específico evangelizador y santificador. En esta línea San Juan Pablo II en un mensaje a la Acción católica italiana, destacó tres grandes características de la parroquia:

La parroquia es la "casa de la comunidad cristiana" a la que se pertenece por la gracia del santo bautismo; es la "escuela de la santidad" para todos los cristianos, incluso para los que no se afilian a movimientos eclesiales 
definidos o no cultivan espiritualidades particulares, es el "laboratorio de la fe", en el que se transmiten los elementos fundamentales de la tradición católica; y es el "gimnasio de la formación", donde las personas se educan en la fe y son iniciadas en la misión apostólica. (Juan Pablo II, 2003b)

En este sentido debemos recordar que el primer anuncio, el anuncio del Evangelio de Cristo no es algo exclusivo del párroco, compromete en corresponsabilidad a todo bautizado y tendría que facilitárseles la posibilidad de prepararse para salir a hacer vivo dicho mensaje.

Una parroquia en la cual los laicos permanecen mudos porque no se arriesgan, porque no saben, porque no se les abre espacio ni se les corresponsabiliza, una parroquia así no podrá estar en condiciones de llevar el anuncio del Evangelio a todas las gentes (Fontana, 2010-2011: 59).

La corresponsabilidad supone la capacitación y la misión de los discípulos de Cristo, por ello la parroquia debe ser esa escuela que los forma y configura a la manera propia de Cristo, debe ser laboratorio donde se componen y recomponen propuestas de acción pastoral parroquial urbana impulsadas desde su dinamismo como discípulos de Cristo, desde la generosidad y con la fuerza del Espíritu Santo; y debe ser palestra o gimnasio que ayuda a ejercitar en el testimonio de los valores evangélicos para la ciudad y sus ciudadanos.

\subsection{Parroquia en red y en comunión de comunidad}

La característica principal de la comunidad parroquial en la ciudad y ante las dinámicas, del anonimato, de la utilidad, de la velocidad, deberá ser la de buscar, ante todo y, sobre todo, en la vida fraterna el corazón del Evangelio.

Para la parroquia de la ciudad "crear redes" es uno de los puntos decisivos. En un mundo donde la Iglesia es cada vez más consciente que no es el único sujeto agente de la sociedad, pero reconoce que es una "minoría calificada", se hace necesario aprender el arte de la colaboración y la capacidad de tejer relaciones en función de un proyecto común, no solo a nivel civil y social, sino también en ámbito ecuménico e interreligioso.

Lejos de pensar que entrar en diálogo con diferentes organismos sociales y civiles signifique perder la propia identidad, algunas Conferencias Episcopales afirman que la capacidad de unir recursos y planificar juntos otros caminos de renovación, ayuda a toda la Iglesia a asumir un auténtico dinamismo "en salida" (Sínodo de los Obispos, 2018: nn. 204-205). 
Esta diversidad de formas, espacios, y posibilidades de comunicación en y de la Iglesia, a través de las cuales se vive la experiencia de la comunión lleva, necesariamente a pensar en la corresponsabilidad eclesial.

Acogiendo la responsabilidad pastoral de la Iglesia, en particular estando a la guía y cuidado de una comunidad eclesial, los pastores han de saber moverse con creatividad y gozo en la cultura actual profundamente marcada por la presencia de los medios de comunicación y del flujo veloz de la información, de las redes telemáticas, de las interconexiones y de la mentalidad de red. No hay necesidad de ser profesionales en este medio, sino buenos observadores que comprenden aquello que sucede a su alrededor y saben guiar sin miedo a la comunidad dentro de esta realidad propiciando las relaciones entre sus miembros y creando las posibilidades para que la comunicación alcance su finalidad de comunión.

Hay que tener en cuenta que ningún espacio virtual o digital reemplaza la presencialidad esencial para la evangelización. Por ello a nivel pastoral y evangelizador se debe procurar que detrás de cada contacto posibilitado a través de las plataformas digitales, siempre haya una relación real, detrás de cada grupo digital haya una comunidad real, porque no es suficiente crear o animar sitios web, estar saturarnos de contactos en las redes sociales, es necesario que en la base de una verdadera evangelización este siempre el testimonio personal (Valero Cárdenas, 2009: 101. 214).

El principio de la encarnación nos ha enseñado que la evangelización está hecha de sudor, de trabajo hombro a hombro. Hay que evitar caer en el extremo de una virtualidad que nos haga perder la dimensión del sacrificio, del esfuerzo, de la entrega, la paciencia, el dedicar tiempo, el compartir, todo ello propio de la presencialidad. Debemos ser conscientes que la conexión digital no basta para tender puentes, no alcanza para unir a la humanidad (Francisco, 2020: n. 43). Por ello debemos trabajar por recuperar la pasión compartida por una comunidad de pertenencia y de solidaridad, a la cual destinar tiempo, esfuerzo y bienes (Francisco, 2020: n. 36).

Tampoco se debe caer en la idea que por obligación todo debe pasar por lo digital. Quien no puede acceder a plataformas digitales para evangelizar, sabe que puede valerse de otros recursos didácticos como revistas, fichas, cuadernillos pensados para los distintos territorios humanos. Hay otros medios, y no porque no sean tan modernos, dejan de ser válidos. 
2.4. La parroquia, armonizadora de vocaciones y carismas al servicio al servicio del anuncio del Evangelio en la ciudad

Pensar en una diversificación y armonización de vocaciones y carismas desde la parroquia para la ciudad es fruto de los constantes retos que se presentan a la cultura urbana, esto pone al centro el deseo y la necesidad de anunciar a Cristo y su Evangelio al gran mundo urbano. Las distintas vocaciones y carismas pueden presentarse en la Iglesia como doble testimonio de entrega al prójimo y la explicita participación en la misión de la Iglesia.

Son diversos los valores eclesiales que se pueden fortalecer con este proceso de armonización de las vocaciones y los carismas al servicio del anuncio del Evangelio en la ciudad. La participación de la comunidad, el asumir corresponsablemente la vida y la misión de la Iglesia, hace que la comunidad reconozca la parroquia como parte de su vida, hace más visible la acción de los miembros, al tiempo que abre caminos para una saludable diversidad y descentralización de los servicios evangelizadores, que van al encuentro de las necesidades propias de cada comunidad.

Las parroquias pueden también nutrirse de la riqueza de los carismas de los religiosos consagrados y de sus testimonios de vida, por ello resulta relevante la vida consagrada presente en la comunidad parroquial enriqueciendo también el programa evangelizador de las diócesis.

\subsection{Parroquia, centro de envío misionero a la ciudad}

La dimensión misionera es una fuerza centrífuga que anima la Iglesia desde dentro, la Iglesia no puede permanecer inmóvil, replegada sobre si misma esperando que los ciudadanos vengan a ella, no puede encerrarse dentro de los círculos restringidos de los creyentes practicantes. La perspectiva misionera exige que la Iglesia tenga una mirada amplia y universal capaz de comprender a todos y transformar todos los aspectos de la vida de la ciudad. La tensión misionera exige interesarse por todos los aspectos de la vida humana: religioso, cultural y social, como el político y el económico. En otras palabras, la misión consiste en llevar los valores del Evangelio al interior de cada sector de la vida pública y privada (FrancisVincent, 2003).

Hoy nuestras parroquias están llamadas a convertirse en verdaderas plataformas misioneras. Cada encuentro parroquial debería impulsar a los fieles a salir hacia el mundo. Justamente a causa de los amplios espacios sociales que los creyentes viven durante la jornada, ellos pueden construir posibilidades de anuncio, de diálogo, de relaciones y de testimonios de fe. 
Por ello las parroquias podrán decir a gran voz Discípulos ja la ciudad! Vayan a predicar el Evangelio y den testimonio de mi amor, en nombre del Padre, del Hijo y del Espíritu Santo, para que quien vea crea, y sean capaces de suscitar o despertar en quienes los escuchan y en quienes los encuentran el don de la fe, y que en este nuevo tiempo en el que Cristo continúa a lanzar el desafío ¿A quién enviaré? sean capaces de decir: ¡Aquí estoy señor, envíame a mí!

2.6. Parroquia, artesana de humanidad y constructora de la paz y del encuentro

Este aspecto de la parroquia hace referencia a la necesidad de conectarnos a la dimensión social de la evangelización sin la cual estaríamos mutilando el Evangelio y, por tanto, su transmisión. "Si esta dimensión no está debidamente explicitada, siempre se corre el riesgo de desfigurar el sentido auténtico e integral que tiene la misión evangelizadora" (Francisco, 2013: n.176).

Esta intervención de la parroquia como artesana de humanidad y constructora de la paz y del encuentro, entra a afirmar la primacía de la persona humana, en su promoción y su progreso dentro de un desarrollo integral y solidario (Vaticano II, 1965: n.12), no meramente asistencialista, pero si asistencial.

En una ciudad globalizada, las parroquias están cada vez más llamadas junto a los discípulos misioneros urbanos, a penetrar el tejido social y a testimoniar su fe, a anunciar el mensaje evangélico de Cristo y a transformar las ciudades con sus propias vidas.

Las parroquias deberán vivir plenamente en lo social los criterios de acogida, caridad y verdad. La acogida como la apertura hacia las personas quien quiera que ellas sean. La caridad como don del amor misericordioso hacia los más vulnerables y, la verdad que debe ayudar a iluminar y a conocer la realidad de la persona humana, urbana y cristiana como de su entorno desde una mirada profética y creyente, para transformar realidades personales y sociales a la manera de Cristo.

Si bien la parroquia concretamente hace una opción por los más vulnerables de la ciudad, también hace una opción por globalizar la solidaridad y la misericordia a través de quienes tienen condiciones de vida diversas y que pueden donarse desde la presencia alegre, acogedora y evangelizadora. 


\section{CONCLUSIONES}

Finalmente puede decirse sintetizando que, la ciudad tiene muchas territorialidades que no siempre coinciden con la territorialidad parroquial, por ello, la parroquia deberá cada vez más integrarse al pueblo de Dios, construyendo y viviendo a fondo la exigencia de las relaciones que ayudan a vivir la exigencia de la vida cristiana. Se deberá acoger la ciudad, con sus dramas, su mezcla de vida y de muerte, de valores y contravalores, que cruzan por sus calles y plazas; sin dejar de descubrir que en la ciudad y en sus territorios locales viven nuestros hermanos y en ella se debe sembrar la Buena Nueva. Deberá estar dispuesta a trabajar en red, siendo capas de sumar esfuerzos para realizar un trabajo pastoral de conjunto inspirado por la creatividad, la inteligencia, el respeto y el compromiso de todos. Por ello también será importante apostar por la formación de los laicos que queriendo comprometerse en el anuncio de Cristo en la ciudad deberán conocer la urbe y sus realidades y hacer nuevos análisis, nuevas síntesis, nuevas propuestas desde el Evangelio, los grandes aportes del Magisterio eclesial y los aportes de otras ciencias para transformar y crear Vida en abundancia en ella.

Comprender la ciudad desde un nuevo paradigma creyente y teológico que reconoce que Dios está presente y vive en la ciudad y entre los ciudadanos, llevará a entender que la parroquia no puede ser concebida solo como el edificio del culto, de los salones, los grupos, como lo expresa Eloy Bueno, sino más bien nos pone ante un nuevo código de sentido de su presencia en la ciudad. Si Dios ya está presente debemos salir para encontrarlo, escucharlo, abrazarlo, curarlo, celebrarlo y crear lazos de encuentro y amistad desde Él. Esto podrá llevar a la parroquia a hacerse vecina de sus vecinos, vecina a sus dificultades, a sus alegrías y gozos. A no concebirse emplazada en un territorio geográfico inmóvil sino pensarse móvil para una cultura de la movilidad.

En este sentido, la parroquia deberá asumir la pedagogía fundamental del diálogo que inspirados en la Gaudium et spes, deberá dirigir la palabra no solo a los bautizados y a los que invocan el nombre de Cristo, sino a todos los seres humanos, creyentes y no creyentes, al mundo de hombres y mujeres de todas las opiniones. Este diálogo requerirá del conocimiento de la realidad de sus habitantes. Sin conocer la cultura de la ciudad y la situación real de las personas, nada será asimilado; pueden implementarse programas, novedades, instituciones, pero sino se hace desde la realidad no ayudará a crecer a las personas, $y$, menos a ser adultos como personas y cristianos (Parrado Carral, 2009: 382).

Por último, la parroquia urbana deberá caracterizarse por la solidaridad evangélica. La solidaridad libera del egoísmo y abre las puertas a la 
empatía, a la caridad, a la acogida sin distinción. Que tenga una mirada profunda para ver con ojos de fe la cultura urbana con la sensibilidad para entablar una relación con ella y sea capaz desde su nuevo estilo, llamar a la conversión y llegar a transformar las ciudades.

La realización de esta misión eclesial exige anteponer tres principios: "la Iglesia debe ser una presencia de comunidad, debe estar siempre en actitud de diálogo y debe constituir una constante presencia de servicio". El seguimiento de estos tres principios permitirá una verdadera presencia de la Iglesia en la ciudad, la realización de su ser signo evangelizador, abandonando los esquemas de la iglesia de cristiandad y siendo sal de la tierra y fermento de la masa. R. Caramuru afirma que es necesario que el pueblo de Dios no se presente como servidor de un grupo, sino para aquel para quien servir es reinar, no busca su interés propio sino la salvación de la ciudad.

\section{REFERENCIAS}

Barreda, J. Á. (2003). El pluriforme testimonio misionero en el mundo de la globalización. Studia Missionalia, 52, 319-346.

Bestard, J. (1984). Desafíos de la nueva realidad urbana a la parroquia. Sal Terrae, 72(9), 665-674.

Calvo Pérez, R. (2016). La conversión pastoral-misionera. Lo que el Espiritu dice a las Iglesias. Burgos: Monte Carmelo.

Consejo Episcopal Latinoamericano. (2007). V Conferencia General del Episcopado Latinaomnericano y del Caribe. Documento conclusivo. Aparecida, 13-31 de mayo. Disponible en https://www.celam.org/aparecida/Espanol.pdf

Conferencia Episcopal de Colombia. (2018). La parroquia en el corazón de la nueva evangelización. Aportes y conclusiones de la CV Asamblea Plenaria del Episcopado Colombiano (febrero del 5-9). Bogotá: CEC.

Congregación para el Clero. (2020). Instrucción. La conversión pastoral de la comunidad parroquial al servicio de la misión evangelizadora de la Iglesia. Disponible en https://press.vatican.va/content/salastampa/es/bollettino/pubblico/2020 /07/20/inst.html

Corraliza, J. A., \& Aragones, J. I. (1993). La psicología social y el hecho urbano. Psicothema, 5, 411-426.

Díaz, C. M. (1996). La parroquia una presencia de la Iglesia en la ciudad. Santander: Sal Terrae.

Domingo, J. R., \& J. L. Segovia Bernabé. (2013). Realidad urbana y parroquia: análisis y contraste. En Universidad Pontificia Salamanca. Instituto Superior de Pastoral, A vueltas con la Parroquia. (pp. 65-120). Estella: EVD.

Fontana, A. (2010-2011). Ridisegnare l'identita dei cristiani in una cultura globalizzata. Catechesi, 80(1), 56-70. 
Francisco. (2013). Exhortación apostólica Evangelii gaudium. Disponible en https://www.vatican.va/content/francesco/es/apost_exhortations/docu ments/papa-francesco_esortazione-ap_20131124_evangelii-gaudium.html

Francisco. (2020). Carta Encíclica Fratelli tutti. Disponible en https://www.vatican.va/content/francesco/es/encyclicals/documents/pa pa-francesco_20201003_enciclica-fratelli-tutti.html

Francis-Vincent, A. (2003). Una Pastorale in prospettiva missionaria. Torino: Leumann, Italia.

González Dorado, A. (1983). Una Iglesia más evangelizadora en las grandes ciudades de América Latina. Revista Medellín, 9(33), 83-116.

Juan Pablo II. (1979). Carta encíclica Redemptor hominis. Disponible en https://www.vatican.va/content/john-paul-

ii/es/encyclicals/documents/hf_jp-ii_enc_04031979_redemptorhominis.html

Juan Pablo II. (1988). Exhortación apostólica post-sinodal Christifideles laici. Disponible en https://www.vatican.va/content/john-paulii/es/apost_exhortations/documents/hf_jpii_exh_30121988_christifideles-laici.html

Juan Pablo II. (2001). Carta apostólica Novo Millennio Ineunte. Disponible en https://www.vatican.va/content/john-paul-

ii/es/apost_letters/2001/documents/hf_jp-ii_apl_20010106_novomillennio-ineunte.html

Juan Pablo II. (2003a). Exhortación apostólica post-sinodal Ecclesia in Europa. Disponible en https://www.vatican.va/content/john-paulii/es/apost_exhortations/documents/hf_jp-ii_exh_20030628_ecclesia-ineuropa.html

Juan Pablo II. (2003b). Mensaje del Santo padre Juan pablo II a la Asamblea Nacional de los Consiliarios de la Acción Católica italiana. Disponible en https://www.vatican.va/content/john-paul-

ii/es/speeches/2003/february/documents/hf_jp-

ii_spe_20030220_azione-cattolica-italiana.html

Maestro, Á. J. (2012). La nueva parroquia Evangelizadora. Renovación Interior y creatividad pastoral. Madrid: Edibesa.

Mancera Casas, J. A. (2015). Panel. Culturas Urbanas: los procesos de la ciudad en perspectiva interdisciplinar. En Consejo Episcopal Latinoamericano, Evangelización en las culturas urbanas. Memorias y compromisos en América Latina y el Caribe (pp. 43-58). Bogotá: Publicaciones CELAM.

Méndez, R. (1990). El fenómeno urbano. Bogotá: Publicaciones CELAM.

Merlos Arroyo, F. (2002). Pastoral del futuro. Tensiones y esperanzas. México: Palabra ediciones.

Niño Sua, F. (1991). La Iglesia en la ciudad. El fenómeno de las grandes ciudades en América Latina, como problema teológico y como desafío pastoral. Roma: Editrice Pontificia Università Gregoriana.

Parrado Carral, M. (2009). Desafíos de la ciudad a la Iglesia en la Evangelización. Misiones Extranjetas, (230-231), 373-383. 
Prat i Pons, R. (2005). Tratado de teología pastoral. Compartir la alegría de la fe. Salamanca: Secretariado Trinitario.

Rincón, A. (1989). La ciudad y las mediaciones. En Cultura urbana, reto a la evangelización. (pp. 121-148). Bogotá: Publicaciones CELAM.

Rodríguez Carrasco, B. (2014). La comunidad parroquial. Perfil pastoral de la parroquia del sacerdote pastor. Material para la reflexión y el trabajo en grupo. Madrid: PPC.

Salamanca Mantilla, P. (2019). Gaudium, La parrocchia quale struttura fondamentale della Chiesa. Simposio sull'Esortazione Apostolica post sinodale Evangelii. Disponible en http://www.pcpne.va/content/dam/pcpne/pdf/Eventi/eg2019/8.\%20Sa lamanca.pdf

Sínodo de los Obispos. (2012). XIII Asamblea General Ordinaria. La Nueva Evangelización para la Transmisión de la Fe Cristiana. Instrumentum Laboris. Disponible en https://www.vatican.va/roman_curia/synod/documents/rc_synod_doc_ 20120619_instrumentum-xiii_sp.html

Sínodo de los Obispos. (2018). XV Asamblea General ordinaria. Los jóvenes, la $\mathrm{fe}$ y el discernimiento vocacional. Instrumentum laboris. Disponible en https://www.vatican.va/roman_curia/synod/documents/rc_synod_doc_ 20180508_instrumentum-xvassemblea-giovani_sp.html

Suess, P. (2010). Parroquia. En P. Suess, Diccionario de Aparecida. 40 palabras claves para una lectura pastoral al documento de Aparecida (pp. 101-104). Bogotá: San Pablo.

Valero Cardenas, Y. (2009). Navegando junto a ti Jesús. Una lectura catequistica sobre los nuevos espacios y las nuevas formas de comunicación de la fe. Bogotá: Ántropos.

Vaticano II. (1965). Constitución pastoral Gaudium et spes. Disponible en https://www.vatican.va/archive/hist_councils/ii_vatican_council/docum ents/vat-ii_const_19651207_gaudium-et-spes_sp.html

Zambrano, F. (2004). La ciudad educadora: símbolos, signos y ritos urbanos para educar al ciudadano. En Educación y Ciudad. Cátedra de pedagogía: Bogotá una gran escuela. Disponible en https://revistas.idep.edu.co/index.php/educacion-yciudad/article/view/291/283 